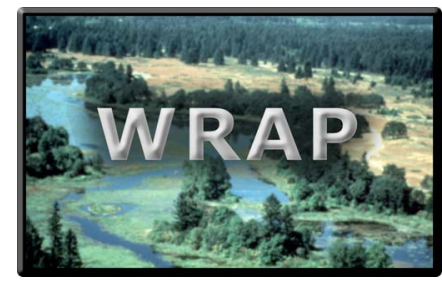

\title{
Availability of a PowerPoint-Based Tutorial on Applying PLOAD for Wetlands Management
}

by Jeff P. Lin and Barbara A. Kleiss

PURPOSE: This technical note announces the availability of an Engineer Research and Development Center (ERDC) PowerPoint tutorial titled "Using PLOAD to Estimate Pollutant Loading into Wetlands." This tutorial, used in conjunction with the existing PLOAD user's manual (http://www.epa.gov/ost/BASINS/b3docs/PLOAD_v3.pdf), is aimed at instructing wetland planners and regulators in using the PLOAD software as a wetlands management and analysis tool.

BACKGROUND: PLOAD is public domain software created by CH2M HILL, and was designed to estimate point and non-point pollutant loading into watersheds. It is an extension of the U.S. Environmental Protection Agency's (EPA's) BASINS watershed and water quality assessment software. Although PLOAD runs within ArcView ${ }^{\circledR}$ 3.x GIS, the end user need not have a working knowledge of the ArcView ${ }^{\circledR}$ software in order to utilize PLOAD.

Although PLOAD was designed for use at a watershed or subwatershed level, it can also be used at a much smaller scale and applied to individual wetlands. Using PLOAD, pollutant loads into wetlands of any size with a defined catchment can be estimated. Also, changes in pollutant loads into a wetland can be estimated for any project affecting land use changes or the incorporation of BMPs in the wetland's catchment.

DESCRIPTION OF THE TUTORIAL: The tutorial is broken into several sections, covering the following topics:

- Description and availability of the PLOAD software.

- Using PLOAD for wetlands management.

- PLOAD data requirements.

- Obtaining necessary data.

- Identifying applicable wetlands.

- Using the "Simple" and "Export Coefficient" calculation methods.

- Incorporating and analyzing the effects of BMPs on pollutant loading.

- Incorporating and analyzing the effects of land use changes on pollutant loading.

For those unfamiliar with using ArcView ${ }^{\circledR}$ 3.x, the main tutorial also contains several optional sections on pre-processing shapefiles for input into PLOAD.

The tutorial focuses on applying PLOAD to wetlands. The tutorial is not meant as a replacement for the PLOAD user's manual, as it does not cover in detail the basics of operating the PLOAD software. 
POINTS OF CONTACT: The tutorial is available online at http://el.erdc. usace.army.mil/wrap/tools. html. This technical note was written by Mr. Jeff P. Lin and Dr. Barbara A. Kleiss, at the Engineer Research and Development Center, Vicksburg, MS. For additional information, contact Mr. Lin (601-634-2068, Jeff.P.Lin@erdc.usace.army.mil) or the Manager of the Wetlands Regulatory Assistance Program, Mr. Robert Lazor (601-634-2935, Bob.L.Lazor@erdc.usace.army.mil). This technical note should be cited as follows:

Lin, J. P. and Kleiss, B. A. (2004). "Availability of a PowerPoint-based tutorial on applying PLOAD for wetlands management," WRAP Technical Notes Collection (ERDC TN-WRAP04-2), U.S. Army Engineer Research and Development Center, Vicksburg, MS. www.wes.army.mil/el/wrap

NOTE: The contents of this technical note are not to be used for advertising, publication, or promotional purposes. Citation of trade names does not constitute an official endorsement or approval of the use of such products. 


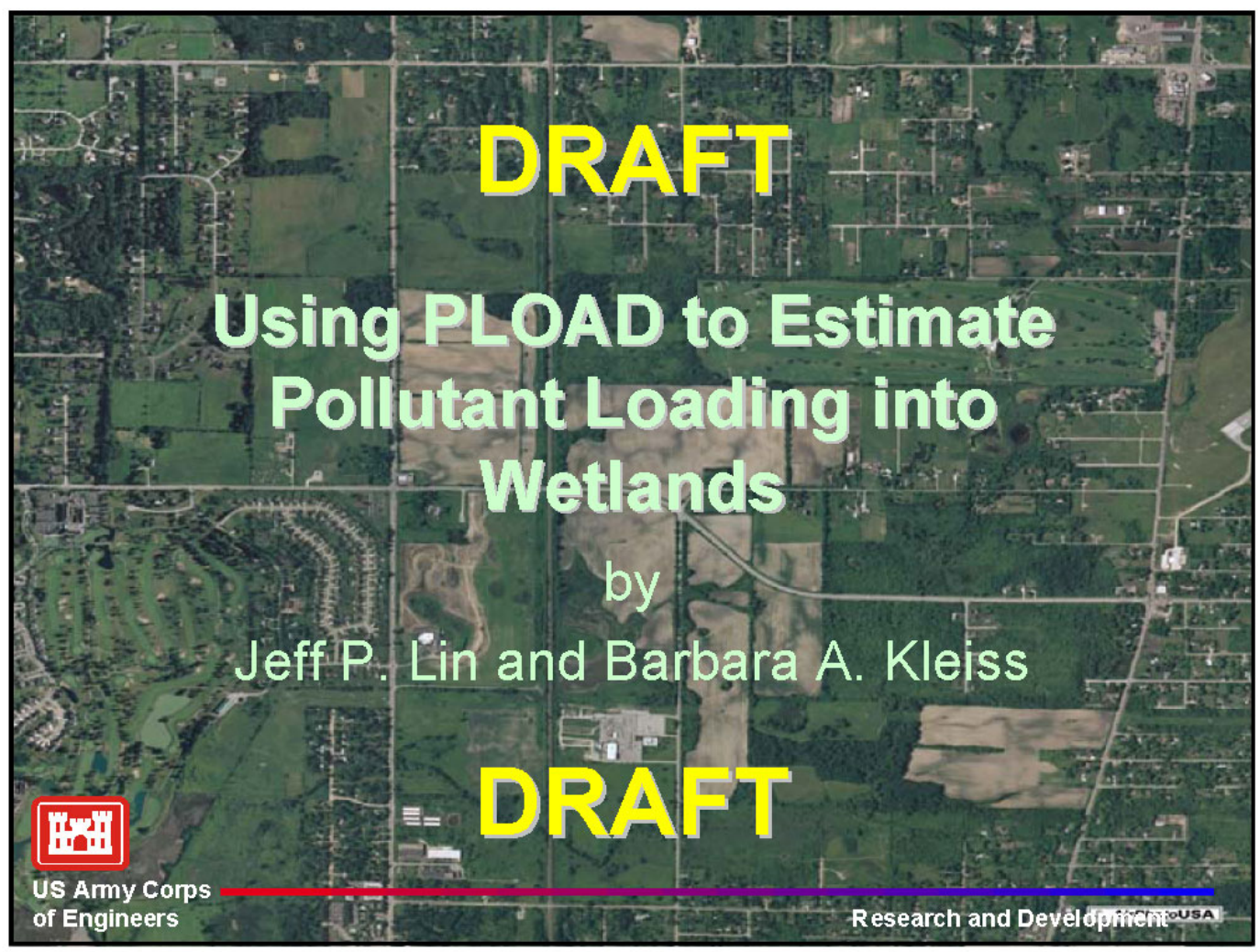

\section{Tutorial Introduction}

The purpose of this tutorial is to introduce the user to the PLOAD software, and demonstrate how to apply it in measuring pollutant loads into wetlands. The tutorial is meant as a supplement, not a replacement, for the existing PLOAD user's manual, and as such, does not cover basic operation of PLOAD software.

There are several reasons that measuring pollutant loading into wetlands might be of interest and concern to those involved with wetland management and regulation.

For example, urban development around a wetland is likely to increase pollutant loads into that wetland. Because heavy pollutant loads may adversely affect wetland functions, estimating the increase in pollutant load due to the development may be of interest for regulatory purposes.

Also, many wetlands can improve water quality by removing pollutants from runoff before they reach a receiving water body. Measuring the potential pollutant load into a wetland can be useful for management purposes by helping planners decide where to create or restore wetlands so that they will provide the most water quality benefit. 


\section{Tutorial Introduction}

PLOAD requires ArcView@ 3.x GIS software to run. Operational knowledge of ArcView 3.x is not necessary in order to run PLOAD. However, some of the geographic coverages used in PLOAD may need to be pre-processed in ArcView before being input to the program. This tutorial contains optional sections on performing some of this processing, for those unfamiliar with using ArcView $B$. The files used in these sections can be downloaded at http://el.erdc.usace.army.mil/wrap/tools.html

Many slides will have the $P$ icon in the upper right corner Clicking on this icon brings users back to the 'Tutorial Sections page. The tutorial also contains many hyperlinks that take users to other sections of the tutorial. Hyperlinks appear as underlined blue font words, like this.

Questions or comments on the tutorial can be addressed to Jeff.P.Lin@erdc.usace.army.mil

\section{Tutorial Sections}

\section{Section 1: Introduction to PLOAD}

\section{Section 2: PLOAD Data Requirements}

\section{Section 3: Identifying Applicable Wetlands}

Section 4: Running PLOAD

\section{Section 5: Choosing a Calculation Method}

Section 6: Incorporating BMPs

Section 7: Incorporating Land Use Changes

Section 8: Sources for Obtaining Data 


\section{Section 1: Introduction to PLOAD}

\section{Section 1: Introduction to PLOAD}

\section{2}

- Calculates pollutant loads for watersheds/basins.

- A simple, screening-level GIS-based model.

- PLOAD is an extension of EPA's BASINS water quality software, available at this website: http://www.epa.gov/docs/ostwater/BASINS/

- PLOAD and BASINS are free, public domain software. 


\section{Section 1: Introduction to PLOAD}

\section{What can PLOAD be used for?}

- Estimating pollutant loads into a wetland from point and non-point sources.

- Estimating changes in pollutant load after incorporation of BMPs.

- Estimating changes in pollutant load due to changes in land use.

- Generating map outputs of pollutant loads by basin.

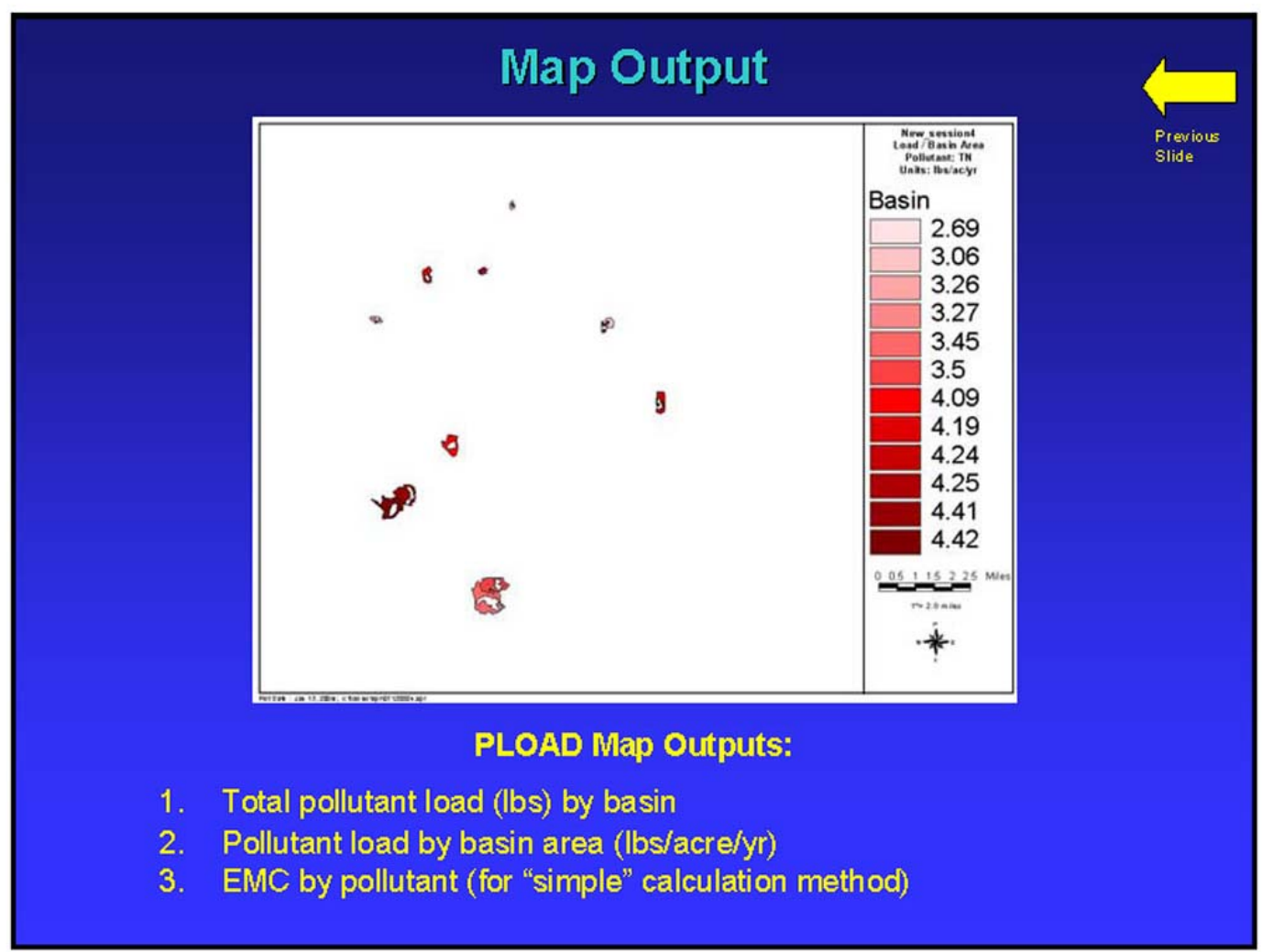




\section{Section 2: PLOAD Data Requirements}

\section{Section 2: PLOAD Data Requirements}

PLOAD calculates pollutant loads using one of two methods:

1. The "Simple" Calculation Method

(Detailed in Section 4)

2. The "Export Coefficient" Method

(Detailed in Section 5)

Different data sets input by the user are needed for each of these methods. 


\section{Section 2: PLOAD Data Requirements}

\section{Required for Both Calculation Methods}

- Watershed/Basin boundaries

- Watershed/Basin land use coverage

\section{Required for "Simple" Calculation Method}

- Annual precipitation data for the area

- Event Mean Concentration (EMC) table for pollutant(s) of interest

- Land use imperviousness table

Required for "Export Coefficient" Calculation Method

- Export Coefficient table

Optional Data for Both Calculation Methods

- BMP efficiency table

- $\quad$ Point source pollutant data table

\section{Section 2: PLOAD Data Requirements}

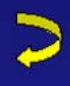

Land Use Coverage

PLOAD requires that the user input a land use ArcView shapefile. The landuse file must cover the entire area of the basin(s) being examined. The land use coverage should also have a corresponding database (.dbf) file, which must contain the following columns:

1. A polygon ID column

2. A land use ID column

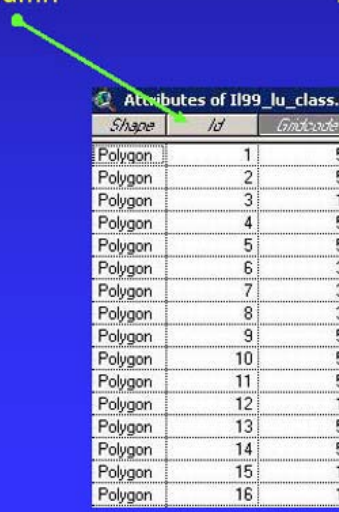

ArcView .dbf file 


\section{Section 2: PLOAD Data Requirements}

Land Use Coverage Example

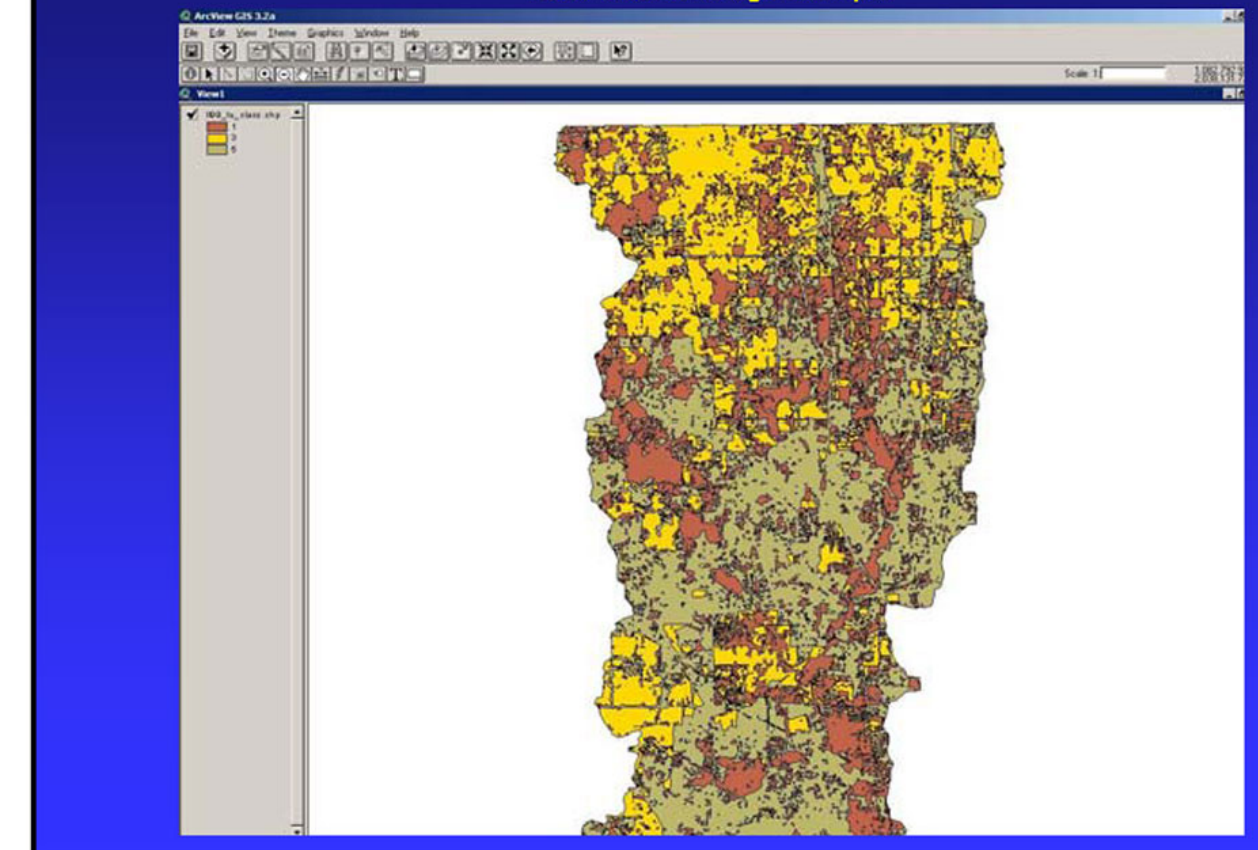

\section{Section 2: PLOAD Data Requirements}

EMC and Export Coefficient Tables

Depending on the calculation method selected, PLOAD requires a user-provided EMC or Export Coefficient Table, in the form of a Microsoft Excel (.XIs) file or a database (.dbf) file.

Both tables must consist of a minimum of two columns:

1. A land use ID column
\begin{tabular}{|c|c|c|c|}
\hline LU_Code & TYPE & TP & TN \\
\hline 1 & FOREST & 0.089 & 2.68 \\
\hline 3 & AGRICULTURE & 0.45 & 4.46 \\
\hline 5 & URBAN & 0.89 & 4.46 \\
\hline
\end{tabular}

This is a sample export coefficient table. Codes used in the land use ID column must correspond to those used in the landuse coverage. dbf file. This sample table has two columns for pollutants, one for total phosphorus (TP) and one for total nitrogen (TN). The numbers in those two columns represent the annual loading rate of those systems, in Ibs/acre. Any other pollutant of interest with a known export coefficient can be added as an additional column(s). EMC tables are identical in form to export coefficient tables, except numbers in the pollutant columns are in $\mathrm{mg} / \mathrm{L}$. 


\section{Section 2: PLOAD Data Requirements}

\section{Imperviousness Factor Tables}

The "simple" calculation method requires that the user input a surface imperviousness factor table.

The imperviousness factor table must consist of a minimum of two columns:

1. A Land Use ID

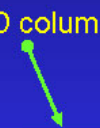

2. An imperviousness factor column

\begin{tabular}{|c|c|c|}
\hline LU_code & TYPE & MPERV \\
\hline 1 & FOREST & 1 \\
\hline 3 & AGRICULTURE & 1 \\
\hline 5 & URBAN & 50 \\
\hline
\end{tabular}

This is a sample imperviousness factor table. Codes used in the land use ID column must correspond to those used in the land use coverage. dbf file. The numbers in the imperviousness factor column represent the percent imperviousness (0-100) associated with each land use. Hence, higher numbers in this column equate to a larger amount of water surface run off for the particular land use.

\section{Section 2: PLOAD Data Requirements}

\section{BMP Tables}

With both calculation methods, the user has the option of incorporating the effects of Best Management Practices (BMPs). Doing so requires that the user input a BMP table, as well as a BMP shapefile.

The BMP table must consist of a minimum of two columns:

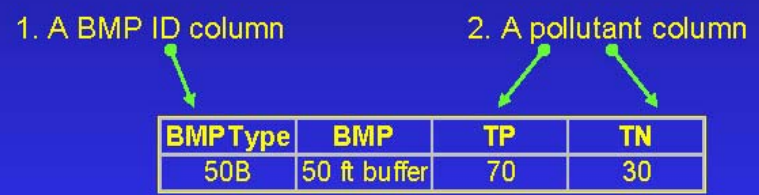

This is a sample BMP table. It has two columns for pollutants. The pollutant column titles must correspond with those used in the export coefficient or EMC table. The numbers in the pollutant columns represent the BMP efficiency rate (percent), so in this example the 50 -ft buffer will remove 70 percent TP and 30 percent TN. Additional BMPs can be added as extra rows in the table. 


\section{Section 2: PLOAD Data Requirements}

Point Source Pollutant Tables

With both calculation methods, the user has the option of incorporating point source pollutant loading. Doing so requires that the user input a point source table, as well as a point source shapefile.

The point source table must consist of a minimum of two columns:

1. A point source ID column

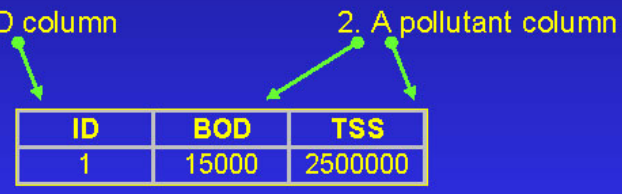

This is a sample point source table. It has two columns for pollutants (BOD and TSS), coming from one point source. Additional point sources can be added as extra rows in the table.

\section{Section 3: Identifying Applicable Wetlands}




\section{Section 3: Identifying Applicable Wetlands}

PLOAD can be applied to any wetland with a defined catchment. The wetland is the lowest elevation in the catchment. Therefore any rainfall within the catchment will run off into the wetland.

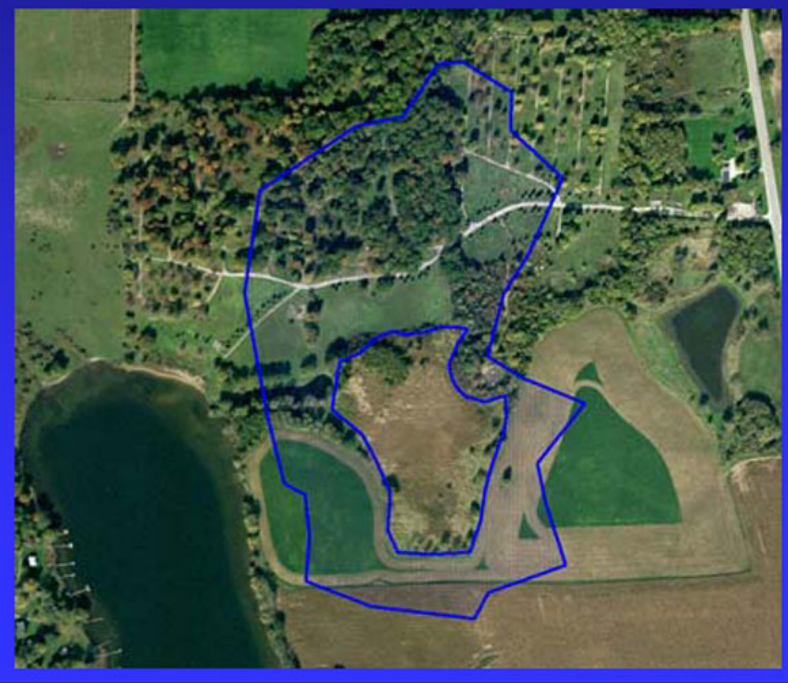

\section{Section 3: Identifying Applicable Wetlands}

\section{Drawing a Catchment:}

If the catchment for the wetland of interest is not already defined, users will need to generate their own. Drawing the catchment will require some form of elevation data. Accuracy of the catchment will depend on the precision of the available elevation data.

Digital 2-ft contour lines work well in most areas, although higher resolution could be needed in areas with very little relief (e.g. floodplains). However, contour data at that detail may not be readily available for all areas.

Another altemative is to use USGS 1:24k topographic maps. These can be obtained through this website: http://hopomaps.usgs.gov

These maps generally contain 5-ft to 10-ft contour lines, and thus may not be as accurate for drawing catchments in flatter regions of the country.

Also, if available, data from a field survey using standard surveying or GPS equipment may be used to determine elevations. 


\section{Section 3: Identifying Applicable Wetlands}

Catchment drawn using digital 2-ft contour lines

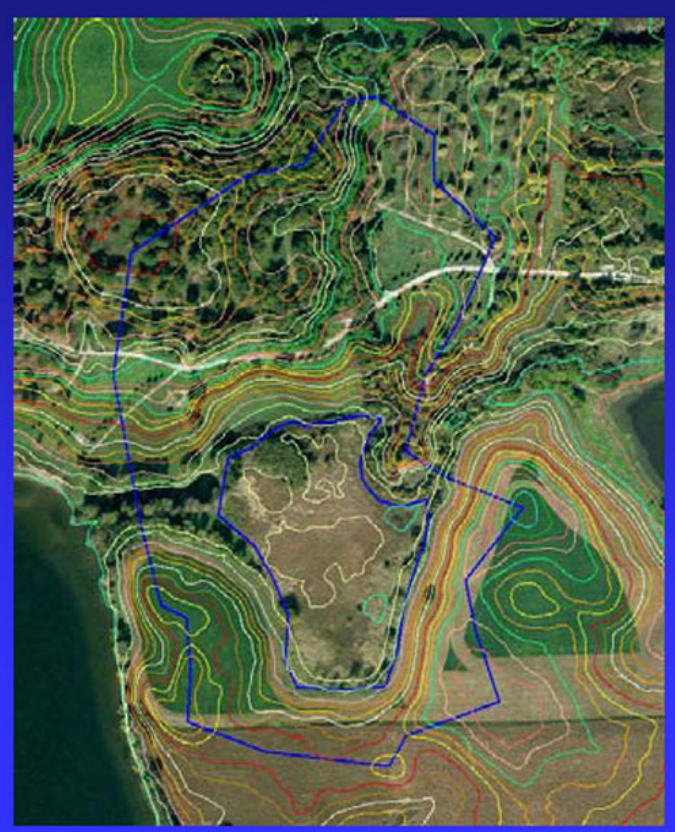

\section{Section 3: Identifying Applicable Wetlands $>$}

Catchment drawn using USGS 1:24k topographic map

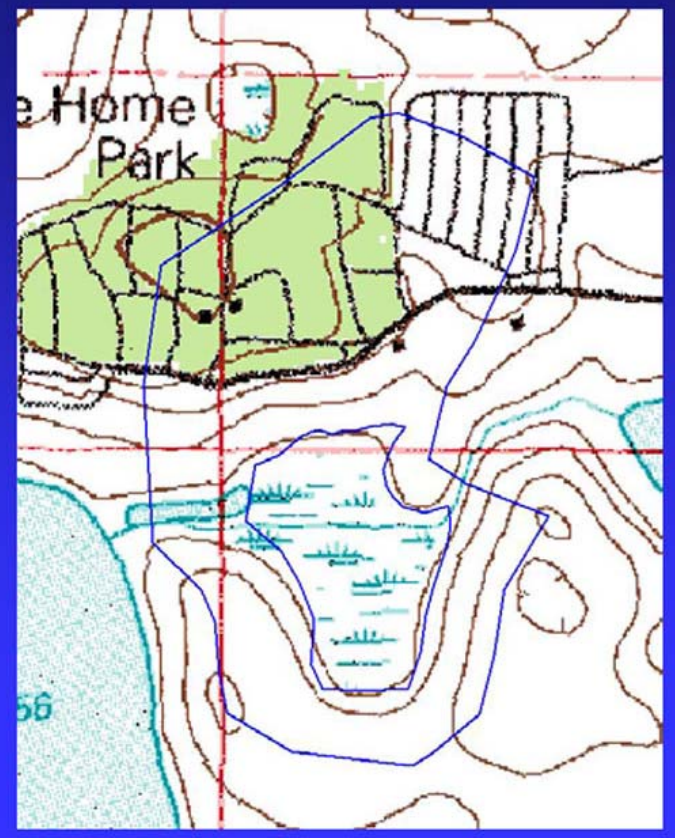


ERDC TN-WRAP-04-2

September 2004

\section{Section 4: Running PLOAD}

\section{Section 4: Running PLOAD}

Shown below is the main PLOAD session screen. From this screen the user can create a new session, input the wetland basins to be analyzed and the appropriate land use data set select the calculation method to be used, and choose whether or not to use BMPs or point source pollutants in the analysis.

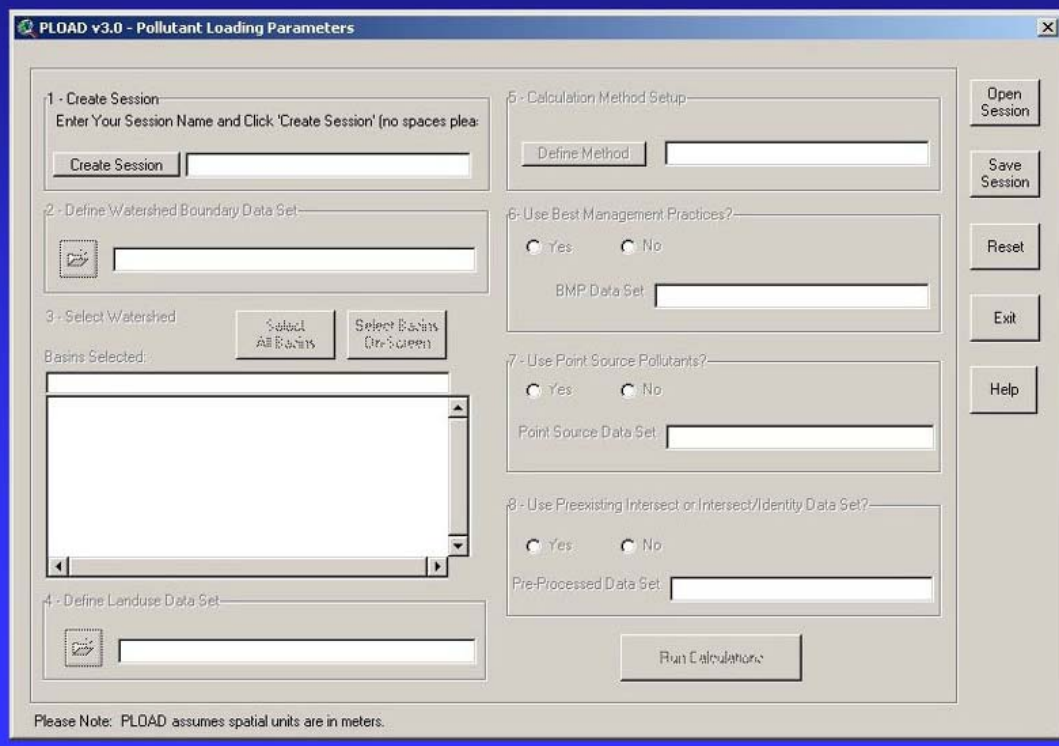




\section{Section 4: Running PLOAD}

PLOAD assumes that the spatial units of the basin(s) and land use shapefile inputs are in meters. If the original input files have different spatial units (feet, for example), they will need to be re-projected into meters. For those unfamiliar with ArcView $\otimes$, a mini-tutorial on re-projecting shapefiles can be accessed by clicking here.

\section{Section 4: Running PLOAD}

The final option on the main PLOAD session screen is whether or not to use a pre-existing intersectridentity data set. In order to perform its analysis, PLOAD intersects the basin boundaries input by the user with the land use file that has been input. This option allows users to input an intersected data set that they have generated on their own, rather than letting PLOAD run the intersection.

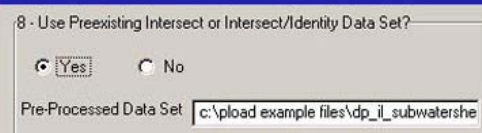

ALWAYS SELECT 'YES' AT THIS SECTION. Due to a potential program 'bug' PLOAD will not generate loading output for small basins if the user selects "No" and lets the program intersect the data. It is unclear exactly how small the basins need to be before this bug manifests itself, but most catchments for individual wetlands are probably small enough for this problem to occur. Therefore, users should always preintersect the land use and basin shapefiles in ArcView, and use that intersected file as the input in this step. For those unfamiliar with ArcView, a mini-tutorial on intersecting shapefiles can be accessed by clicking here 


\section{Section 5: Choosing a Calculation Method}

\section{Section 5: Choosing a Calculation Method}

PLOAD will calculate pollutant loads based on one of two user-selected methods: the "simple" calculation method or the "export coefficient" calculation method.

Selecting a method will largely depend on the land use composition and size of the wetland basin(s) being studied, as well as data availability for the area.

The next two slides summarize the utility of each of these methods. The actual mathematical formulas used in these methods are detailed in the PLOAD user's manual. 


\section{Section 5: Choosing a Calculation Method}

\section{The "Simple" Calculation Method}

- This method is applicable only for drainage areas of less than 1 square mile.

- The "simple" method requires event mean concentration (EMC) data. Because EMC data are generally available for urban land use types, this method is best suited for wetlands located in urban environments.

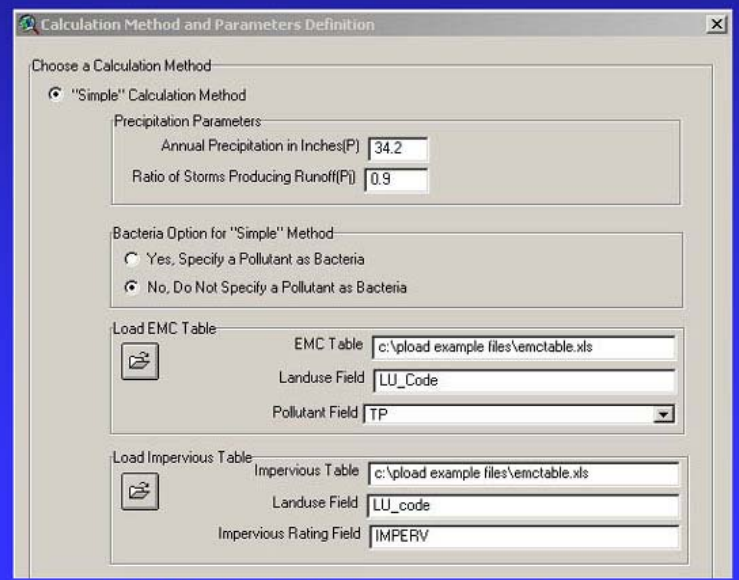

PLOAD "simple" calculation input screen

\section{Section 5: Choosing a Calculation Method}

\section{The "Export Coefficient" Calculation Method}

In most situations, the "export coefficient" method will be the preferred way to calculate pollutant loads into the wetland. Using this method requires export coefficients. This method works for areas containing mixed land use, and the drainage area can be of any size. This method also requires fewer data inputs than the "simple" calculation method.

6. "Export Coefficient" Calculation Method

Load Export Coefficient Table

Export Coefficient Table $\longdiv { \text { c:lpload example fileslexportcoefficient_table.xk } }$
Landuse Field $\longdiv { \text { LU_Code } }$
Pollutant Fielc $\longdiv { T P }$

PLOAD "Export Coefficient" calculation input screen 


\section{Section 6: Incorporating BMPs}

\section{Section 6: Incorporating BMPs}

To the right is a graphical example of how BMPs can be incorporated into any analysis. In this case, a wetland is contained in a small catchment consisting largely of farmland, with smaller urban and forested areas. Prior to implementation of any BMP. PLOAD calculates an estimated TN loading into the wetland of 4.24 Ibs/acre/yr from the catchment After implementing a 50-ft vegetative buffer (with an assumed BMP TN efficiency of 70 percent $^{1}$ ) around the wetland. TN loading has decreased to $2.97 \mathrm{lbs} / \mathrm{acre} / \mathrm{yr}$.

'BMP Efficiency rate obtained from $\mathrm{CH} 2 \mathrm{MH} \amalg$ Technical Memorandum No. 8. Watershed

Modeling.

hittp:liprojects ch 2m.comWakeCounty/DocsTM8_m odel $\% 20$ assumptions.pot

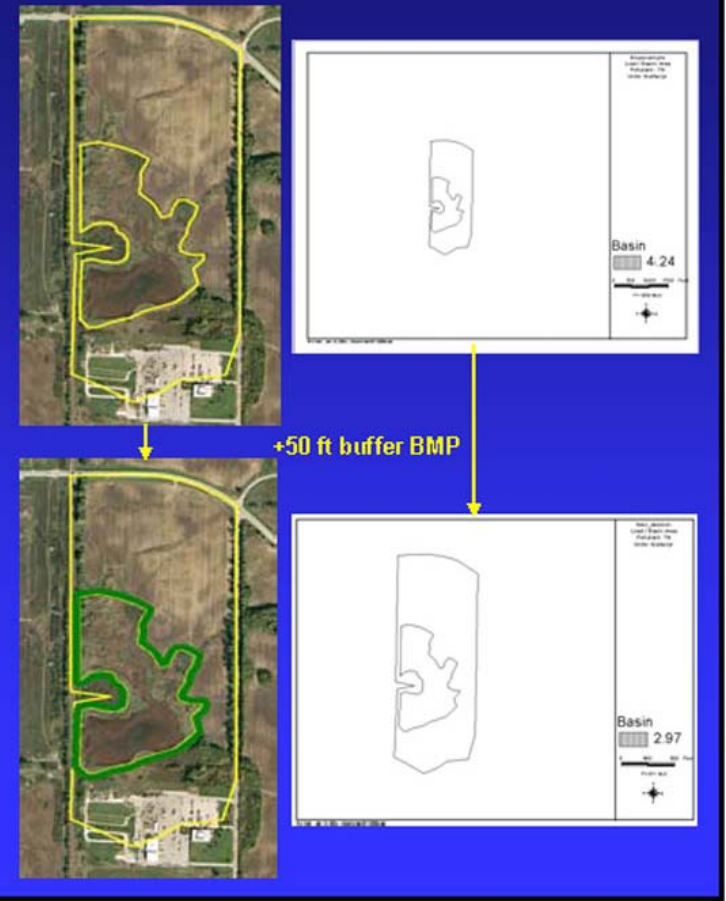




\section{Section 6: Incorporating BMPs}

Incorporating BMPs into PLOAD requires two files: a BMP shapefile and a BMP table

Although the BMP shapefile can be either a point or polygon coverage, the author has encountered problems in using point coverages and therefore recommends polygon coverages.

The BMP shapefile input is the area served by the BMP. In the example in the previous slide, the $50-\mathrm{ft}$ buffer BMP is reducing runoff to the wetland from the entire catchment. In order to simulate this effect, the inputted BMP shapefile is the same size and shape as the catchment itself. The BMP type names in the associated .dbf file must be identical to those used in the BMP table.

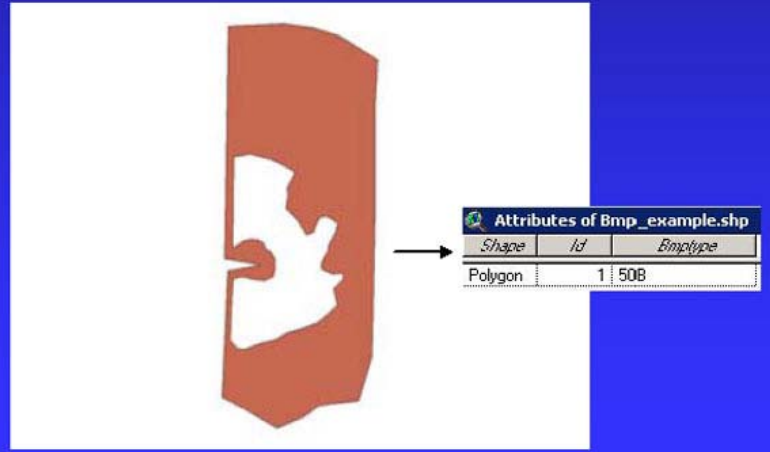

BMP shapefile used in example on previous slide, with associated dbf file.

\section{Section 7: Incorporating Land Use Changes}




\section{Section 7: Incorporating Land Use Changes}

PLOAD can also address the effect of changes in land use on pollutant loading into the wetland.

In order to perform this analysis, the user must first incorporate the changes into the land use shapefile input to PLOAD. This can be done by using the polygon edit feature in Arc View $B$. For those unfamiliar with running ArcView, a mini tutorial can be accessed by clicking here.

To analyze changes in pollutant loading due to altered land use, PLOAD must be run twice; once with the original land use input file, and then again with the new landuse file. The outputs from the two iterations can then be compared to evaluate changes in pollutant loading.

The next slide is an example of using PLOAD to measure changes in TP loading due to urban development in an agricultural area.

\section{Section 7: Incorporating Land Use Changes}
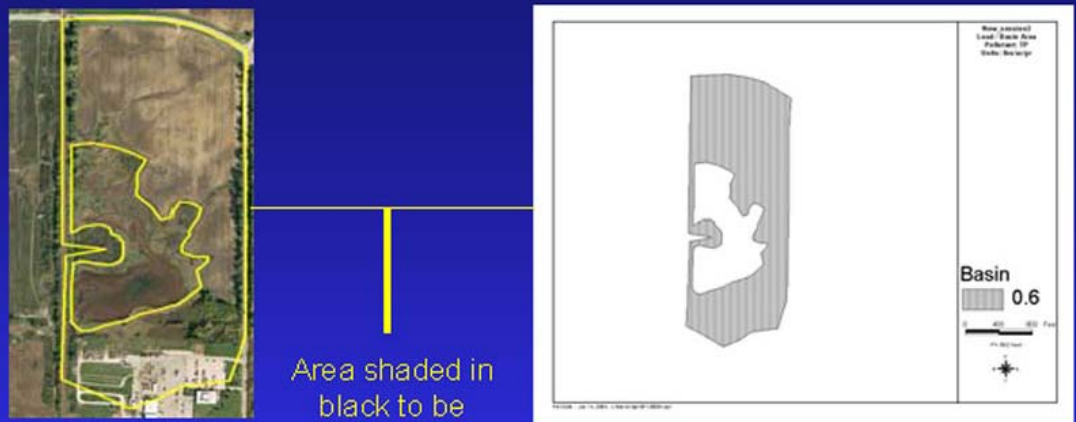

black to be

changed from
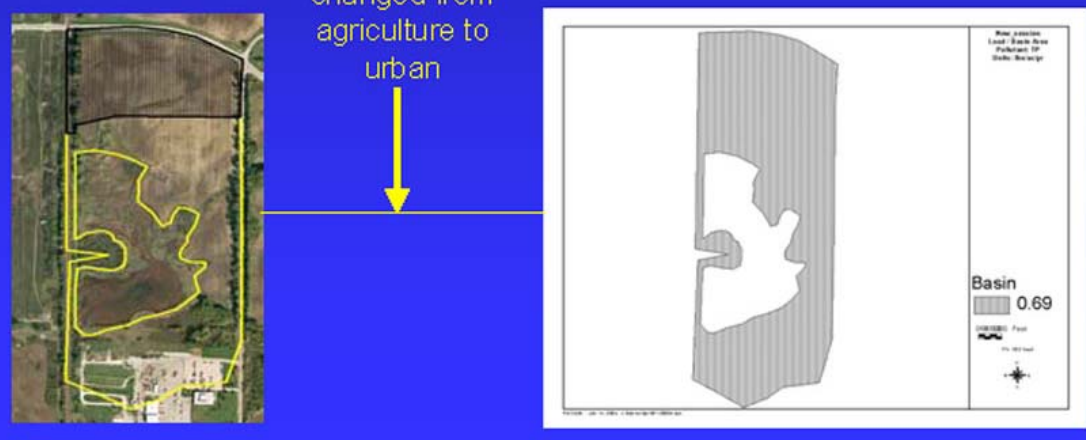


\section{Section 8: Sources for Obtaining Data}

\section{Section 8: Sources for Obtaining Data}

EMC and Export Coefficient Data:

The back of the PLOAD user's manual provides EMC and export coefficient data and references for several areas of the country, although this is far from being a comprehensive list.

A technical note by Lin (ERDC/TN WRAP-04-3) provides additional sources for EMC and export coefficient values, as well as guidance on how to select appropriate numbers.

\section{Land Use Files}

Many states maintain their own web-based GIS data clearinghouses. These websites are usually a good source for obtaining local and regional land use coverages. The following website:

http://ibraries.mit.edu/gis/data/statecenter.html contains links to many of these state GIS websites. 
ERDC TN-WRAP-04-2

September 2004

\section{Changing the PLOAD Land Use Input File using ArcView@ 3.X

This mini tutorial will cover the process of altering the land use input file in PLOAD to

reflect a land use change in the catchment, as shown below. In this example, the land

use at the top of the catchment will be changed from part agriculture to entirely urban
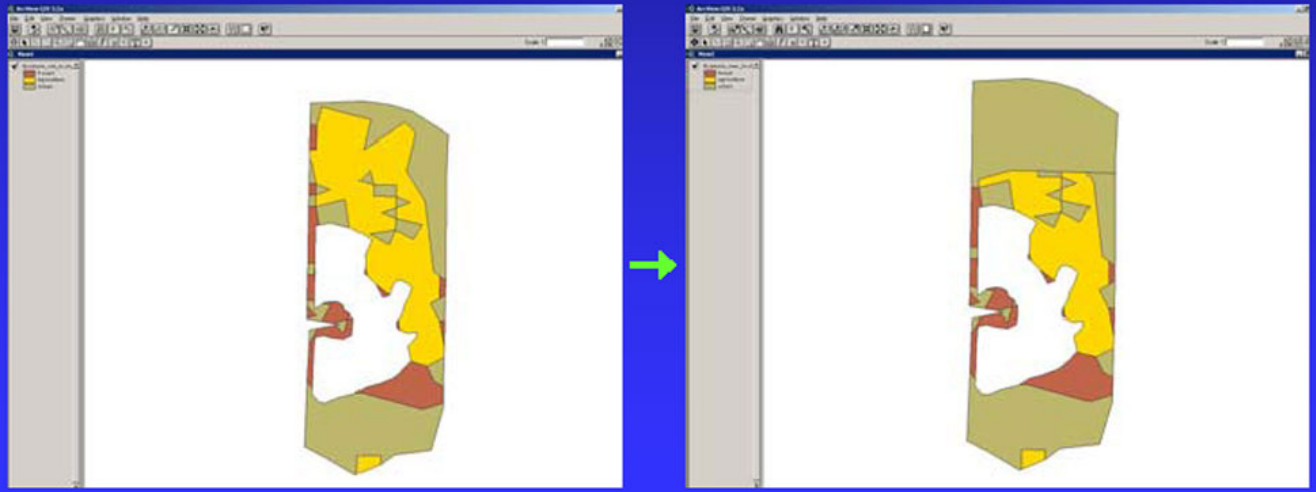

\section{Changing the PLOAD Land Use Input File using ArcView@ 3.x

Step 1: First, open the "example_old lu.shp" file. Then, under the "Theme" menu at the top of the screen, select "Start Editing.

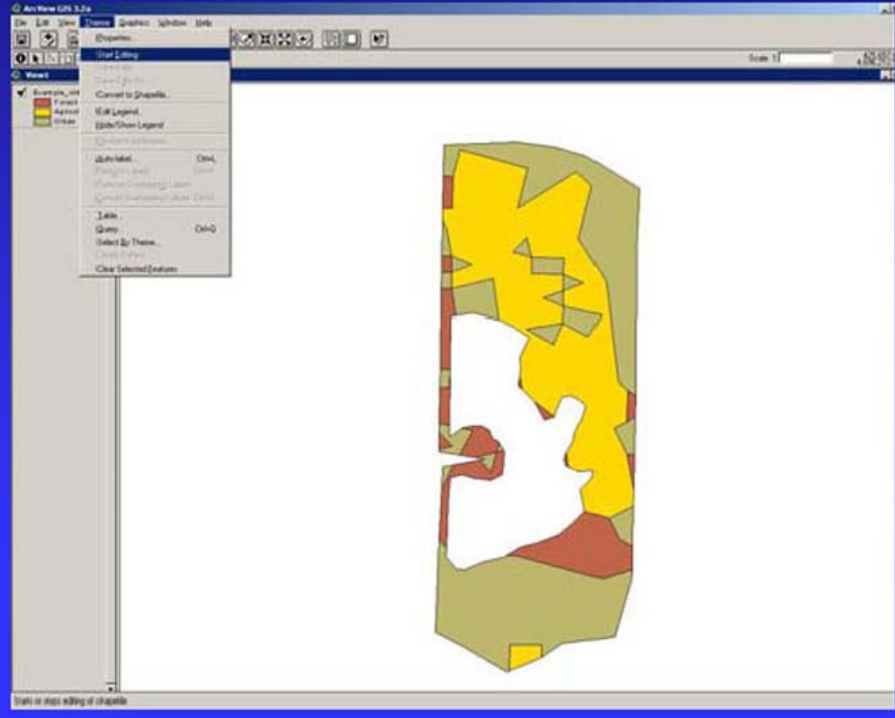




\section{Changing the PLOAD Land Use Input File using ArcView@ 3.x

Step 2: Under the "Draw Rectangle" icon at the top of the screen, select the "Split Polygon" icon.

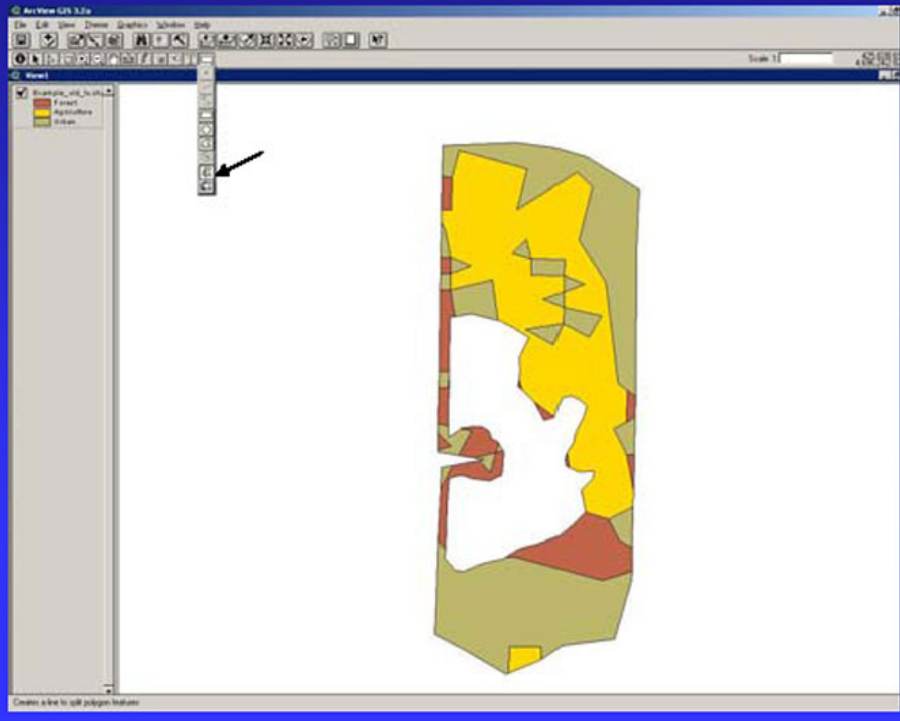

\section{Changing the PLOAD Land Use Input File using ArcView@ 3.X

Step 3: Use the mouse to draw a line marking the border of the area that will have a change in land use. Double left click to confirm the line.

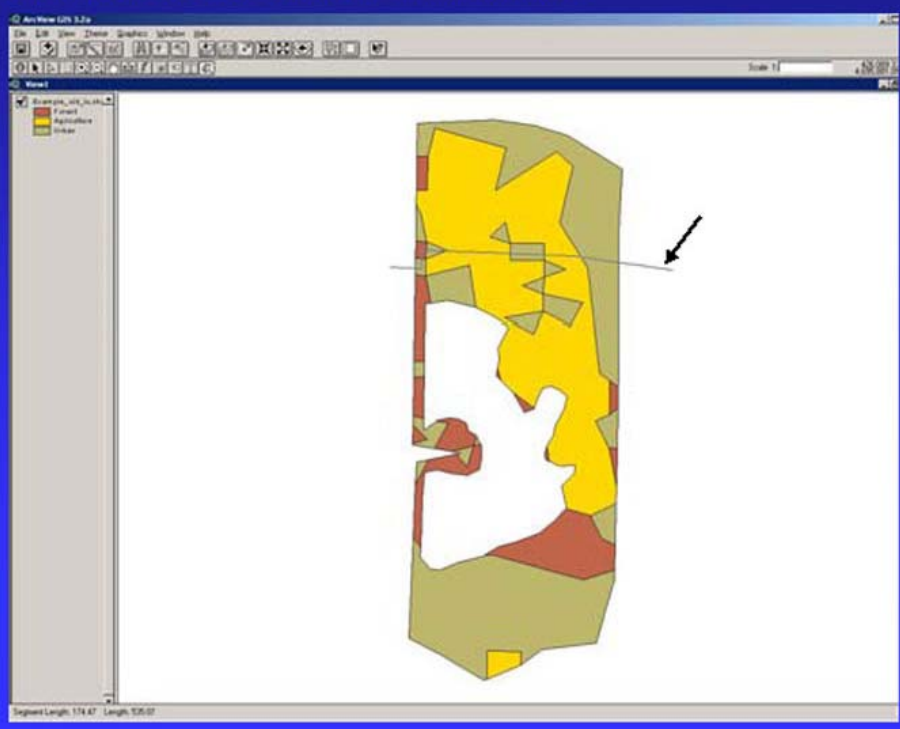


ERDC TN-WRAP-04-2

September 2004

\section{Changing the PLOAD Land Use Input File using ArcView@ 3.x

Step 4: Click on the "select feature" command

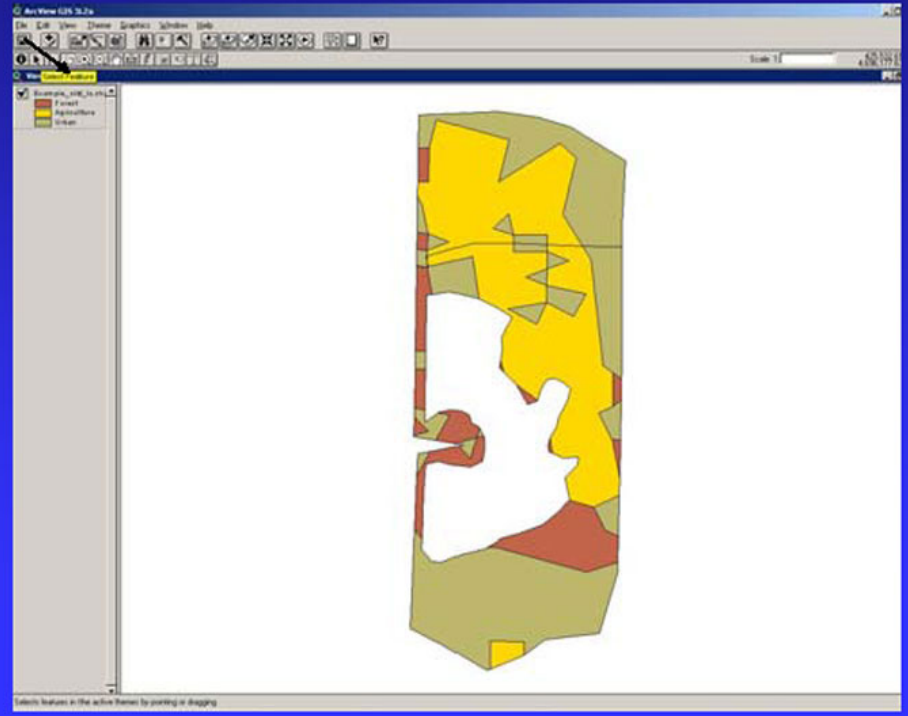

\section{Changing the PLOAD Land Use Input File using ArcView@ 3.X

Step 5: Use the mouse to draw a rectangle around the polygons that need to be changed. Alternatively, individual polygons can be selected by left clicking on them with the mouse. Holding down the "Shift" key while clicking allows users to select multiple polygons using this method.

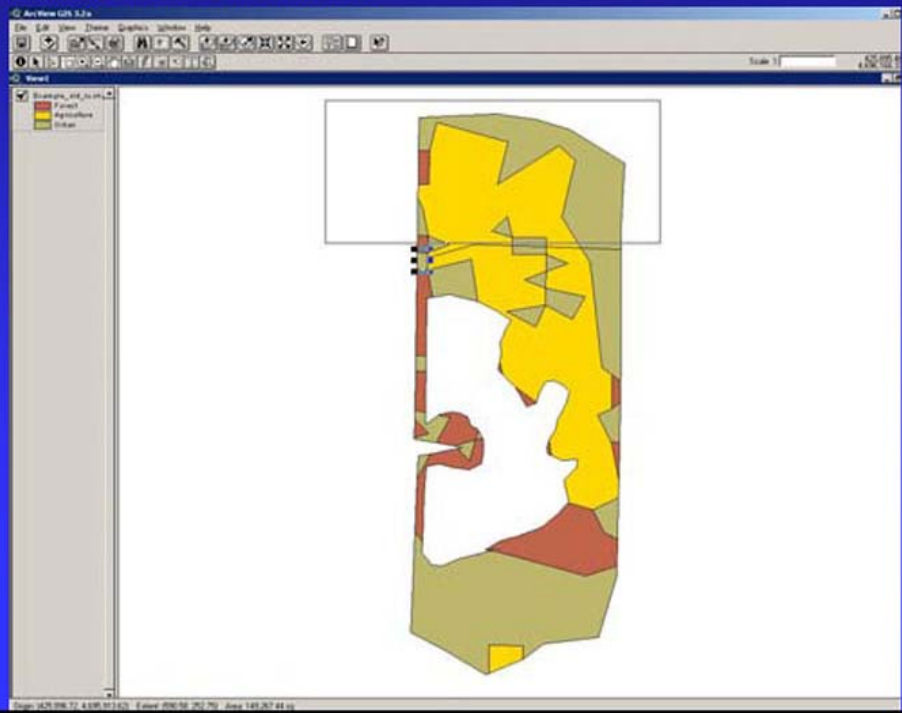




\section{Changing the PLOAD Landuse Input File using ArcView@ 3.X

Step 6: Under the 'Edit' menu at the top of the screen, select 'Union Features.'

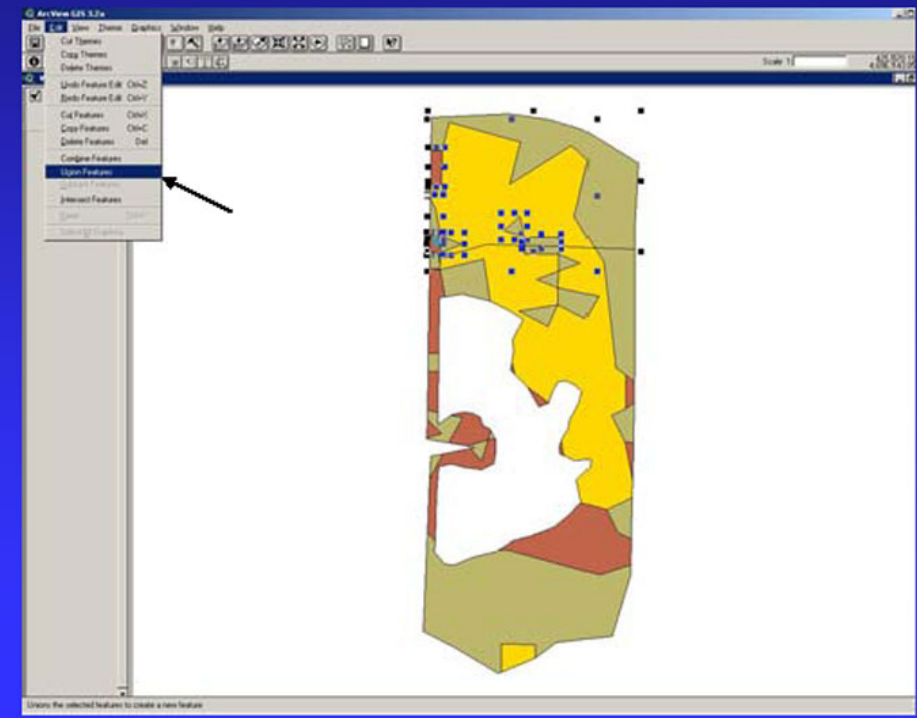

\section{Changing the PLOAD Land Use Input File using ArcView® 3.X

Step 7: Select the "Open Theme Table" icon.

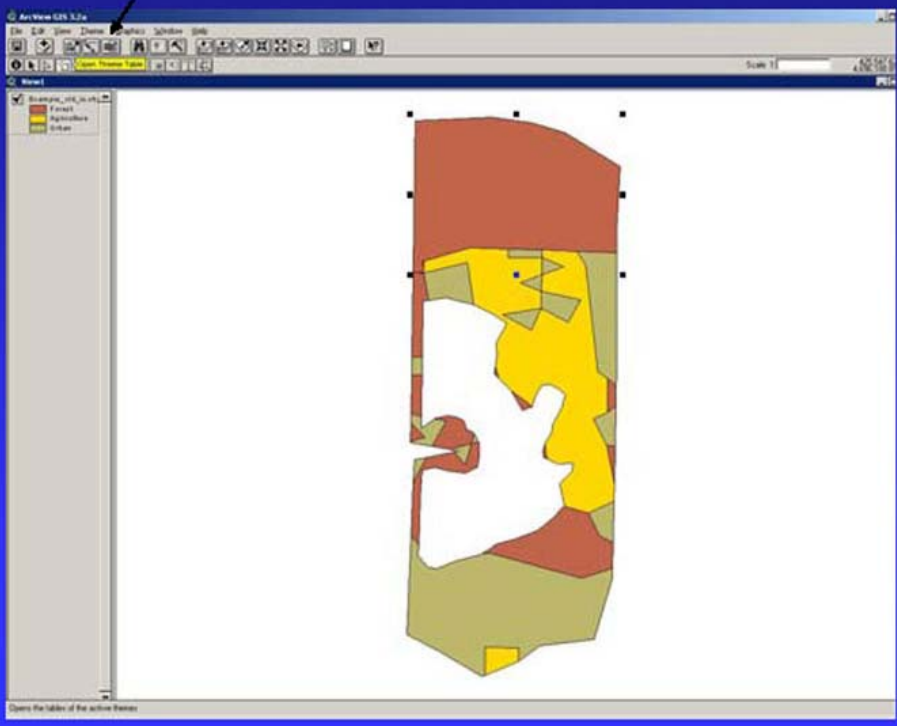




\section{Changing the PLOAD Land Use Input File using ArcView@ 3.x

Step 8: When the theme table opens, the new polygon that was created should be highlighted in yellow at the bottom of the screen. Select the "Edit" icon at the top of the screen.

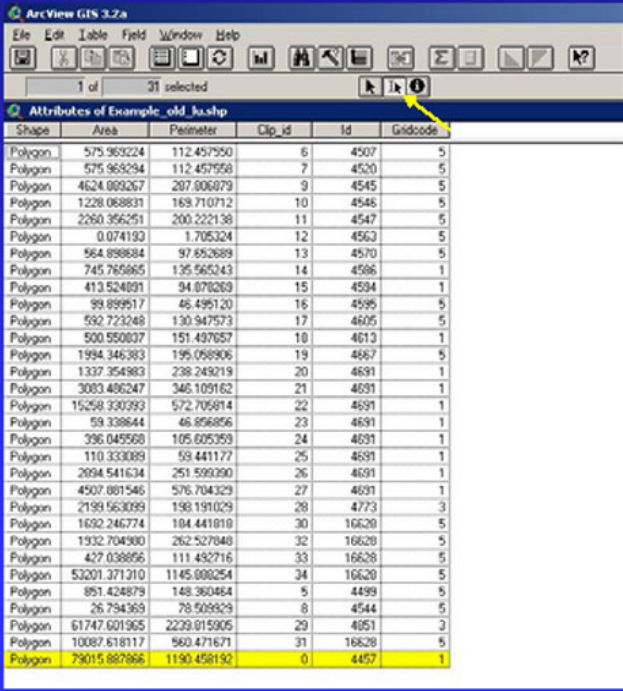

\section{Changing the PLOAD Land Use Input File using ArcView $3 . x$

Step 9: Change the old land use code to the new land use code.

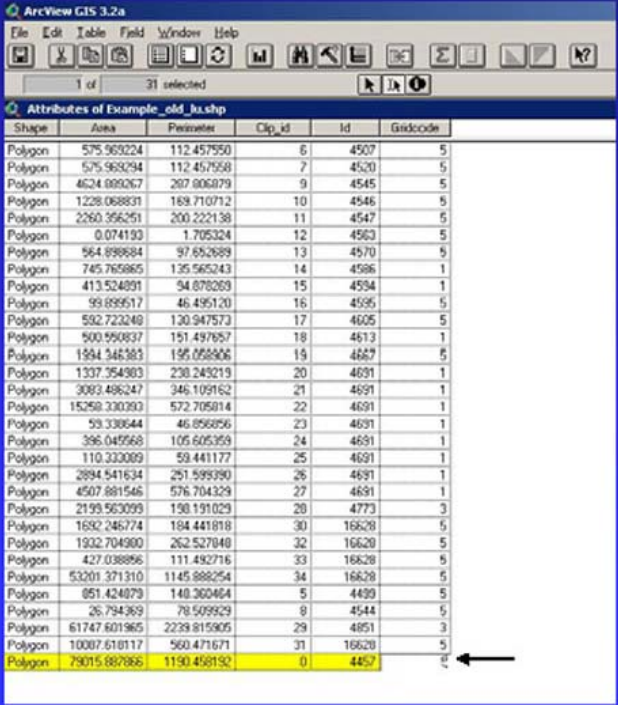




\section{Changing the PLOAD Land Use Input File using ArcView@ 3.x

Step 10: Close the theme table. On the map screen, select "Save Edits As" from the "Theme" menu at the top of the screen. Save this shapefile under a new name. This new shapefile can now be used as the "altered land use" input in PLOAD.

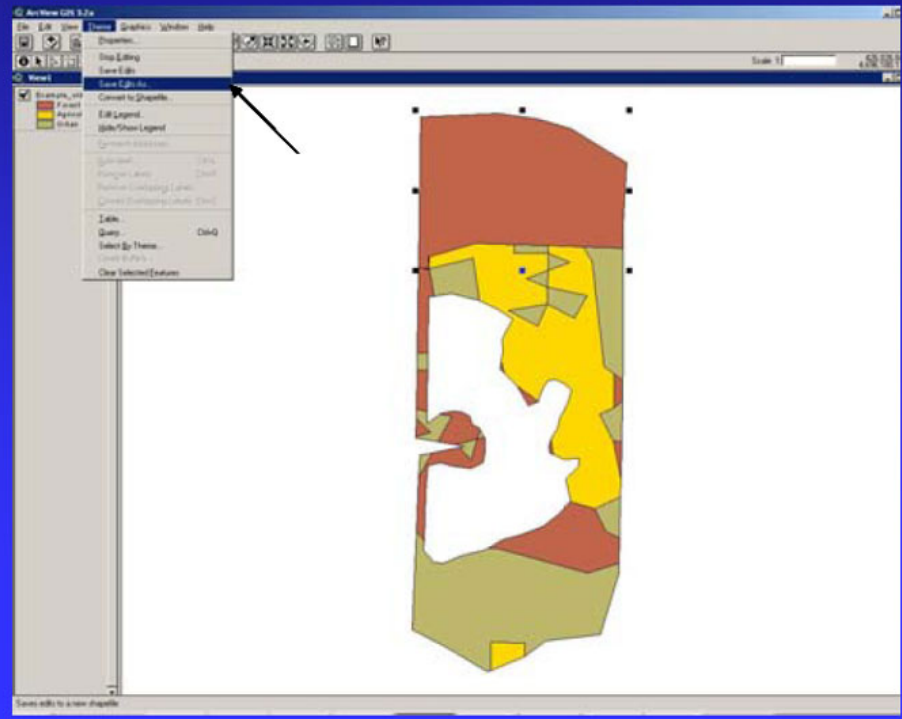

\section{Intersecting Shapefiles Using ArcViewß 3.x}

Step 1: Under the 'View' menu at the top of the screen, select 'Add Theme.' When the 'Add Theme' menu appears, select the land use (dp_watershed_lu shp)) and basins (example_catchment.shp) shapefiles, then click 'OK' to add them to the view.

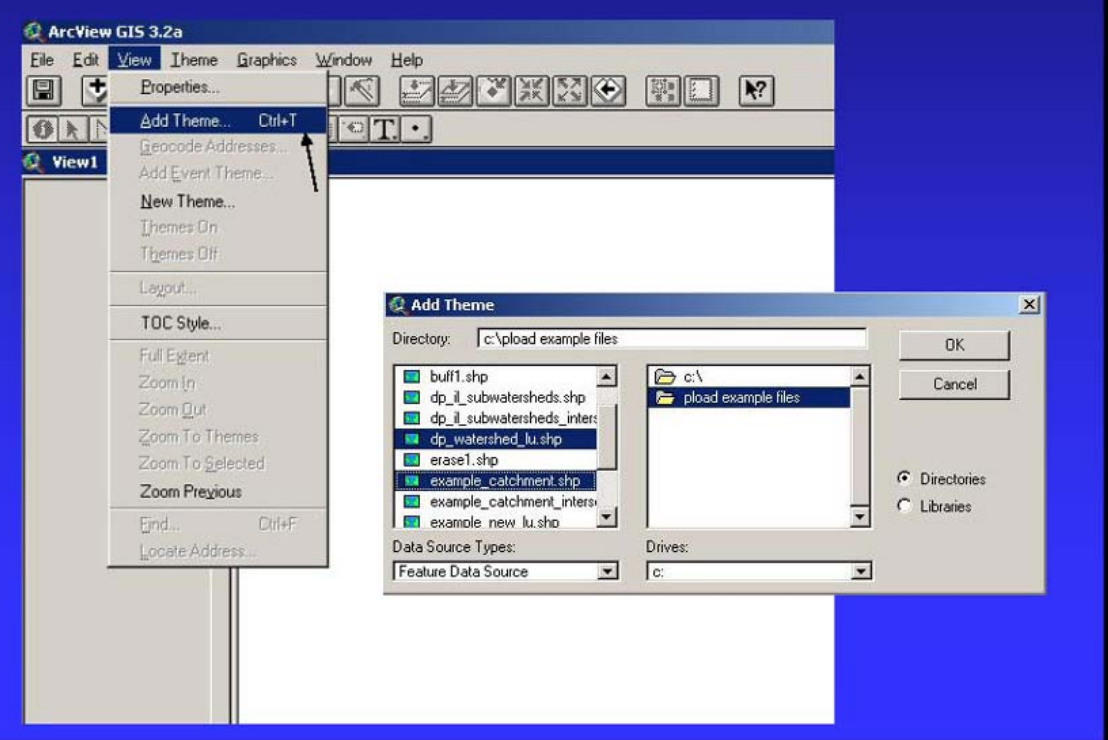




\section{Intersecting Shapefiles Using ArcView® 3.x}

Step 2: Under the 'File' menu at the top of the screen, select 'Extensions.' When the Extensions window opens, click on the 'Geoprocessing' extension.

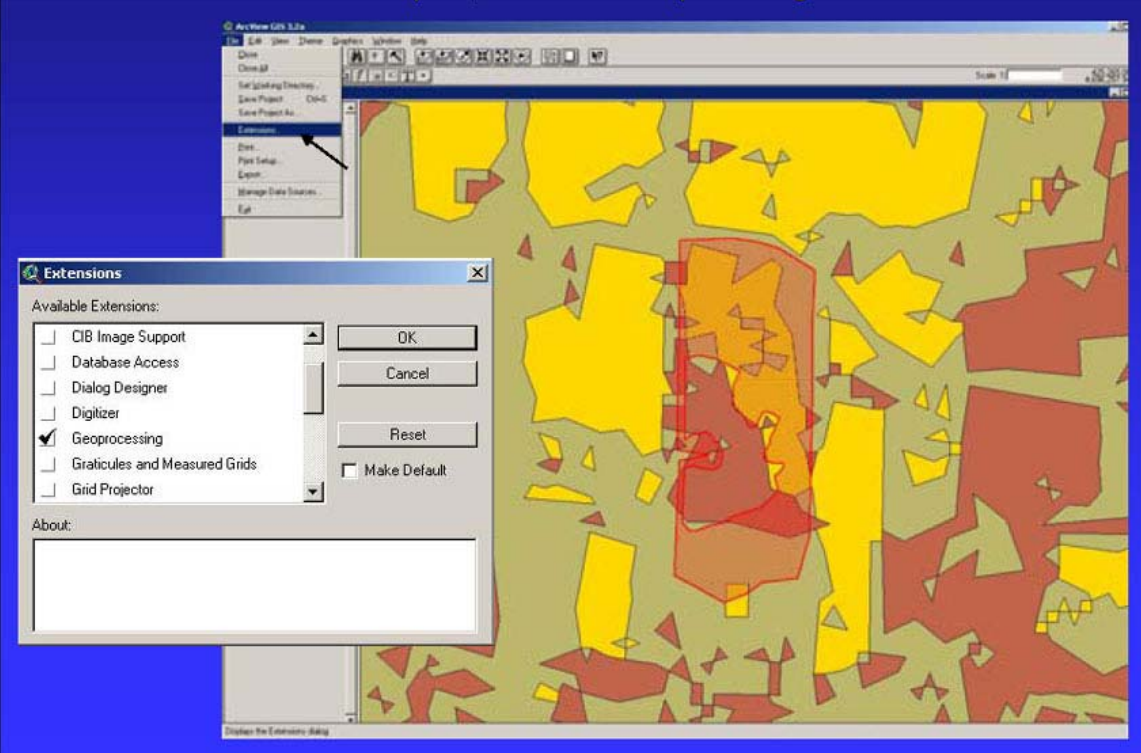

\section{Intersecting Shapefiles Using ArcView® 3.X}

Step 3: Under the 'View' menu at the top of the screen, select 'GeoProcessing Wizard.' When the 'Geoprocessing' window opens, select 'Intersect two themes,' then press the 'Next' button.

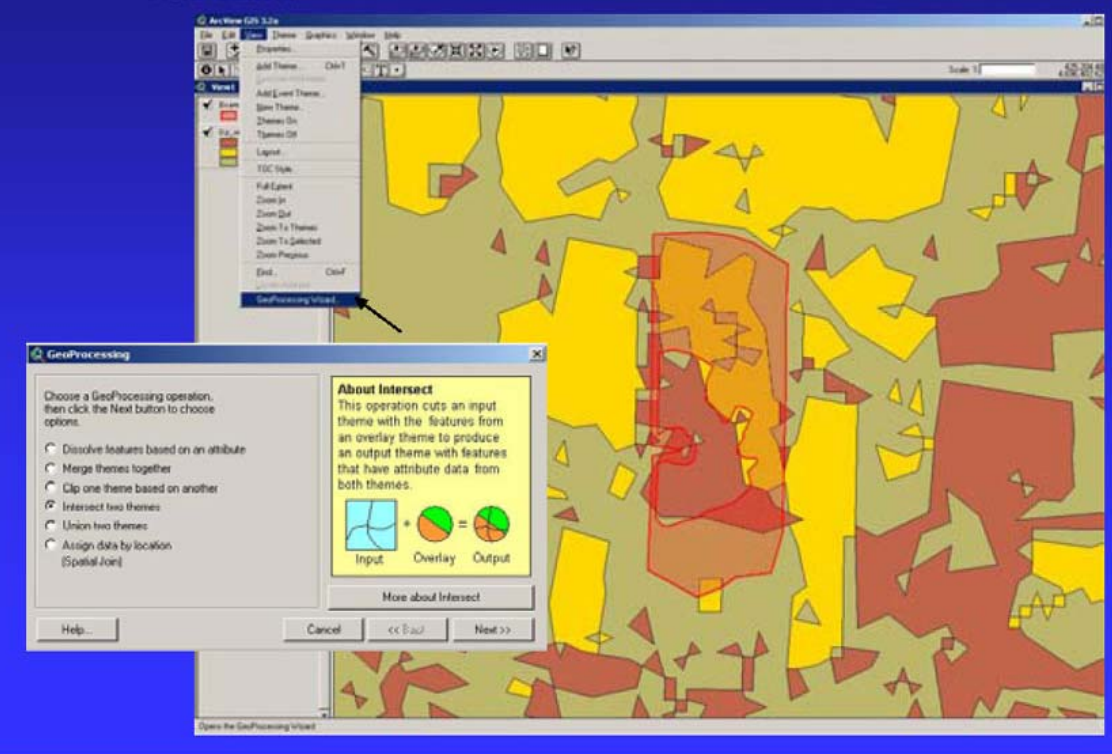




\section{Intersecting Shapefiles Using ArcView® 3.x}

Step 4: Under 'Select input theme to intersect,' select the landuse file. Under 'Select an overlay theme,' select the basin(s) file. Choose a name for the new file, and click the 'Finish' button. This new file can now be used as the pre-intersected file when running PLOAD.

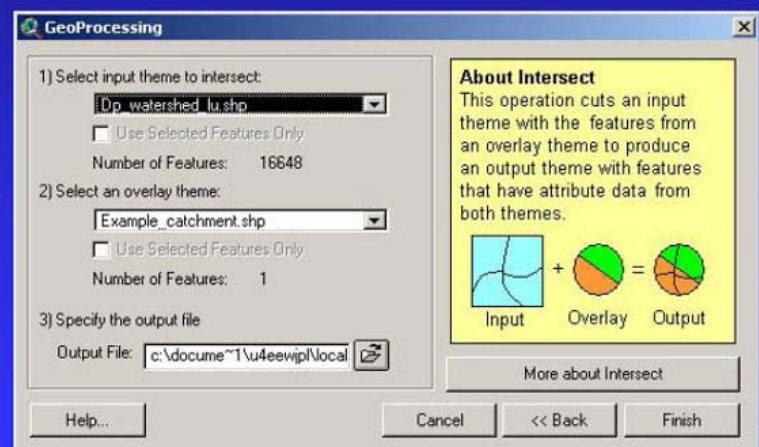

\section{Changing Projections in ArcView@ 3.x}

Changing the projection of shapefiles in ArcView 3.x requires that the original projection of the shapefile is known. Because ArcView shapefiles do not store projection information, the original projection information needs to be obtained from previously documented sources, such as an associated metadata file. Most shapefiles downloaded from government GIS clearinghouses will have this metadata available.

In the following example, we will change a shapefile from IL East 1983 State Plane (feet) projection to UTM 1983 (meters) projection.

Step 1: Under the 'File' menu at the top of the screen, select 'Extensions.' When the Extensions window opens, click on the 'Projector!' extension.
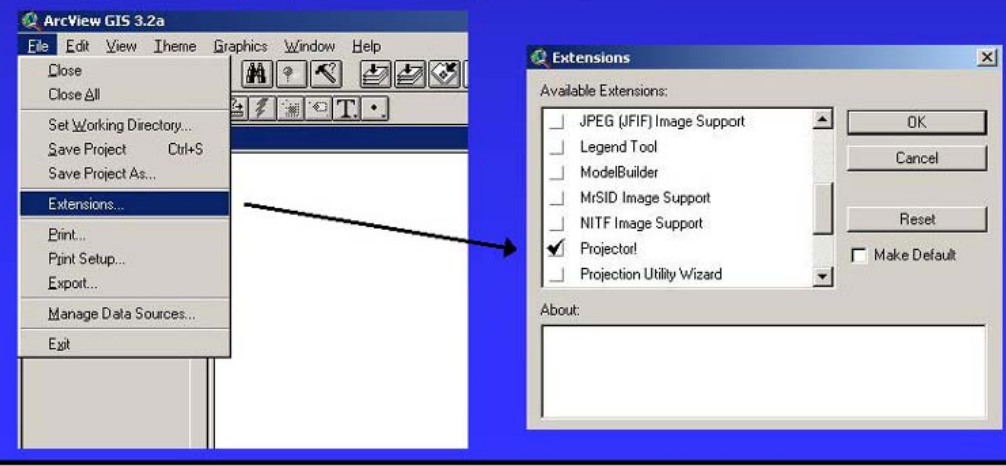
ERDC TN-WRAP-04-2

September 2004

\section{Changing Projections in ArcViewß 3.x}

Step 2: Under the 'View' menu at the top of the screen, select 'Properties.' When the 'View Properties' screen appears, for 'Map Units,' select the map units of the current projection. In this example, the current map units are in feet. Press 'OK' when done.

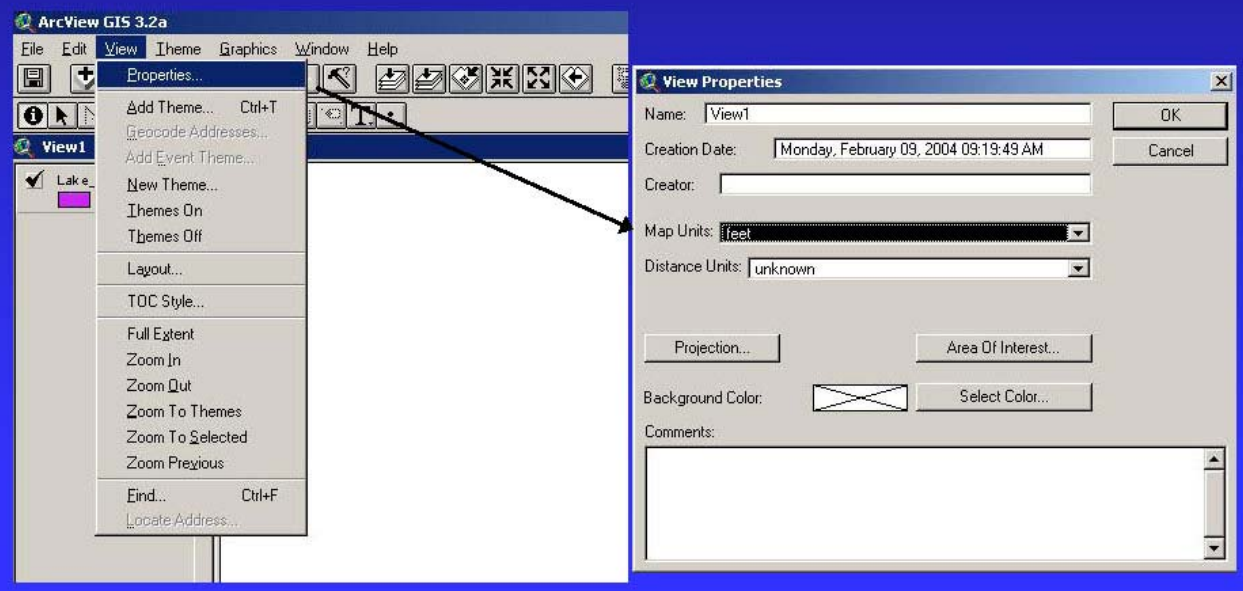

\section{Changing Projections in ArcView® 3.X}

Step 3: At the top of the screen, click on the 'Projector!' icon.

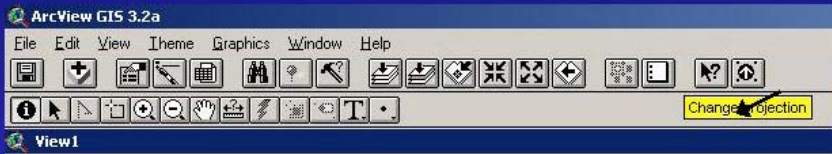
Q view1

Step 4: When the first 'Projection Properties' menu appears, select the current projection of the shapefile. In this case, it is 1983 State Plane, Illinois East. Press OK.

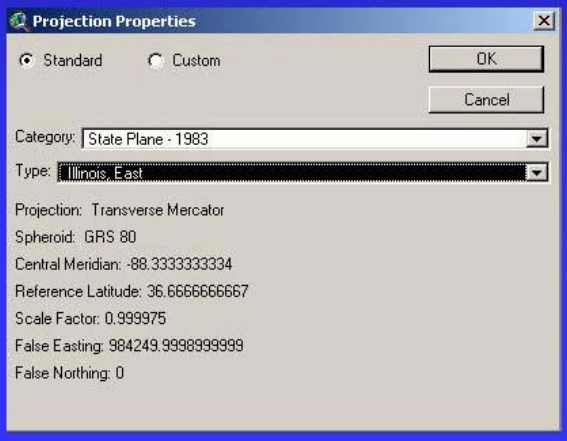




\section{Changing Projections in ArcViewß 3.x}

Step 5: The next menu will ask you to select the map units of the new projection. For the purposes of PLOAD, always select meters.

\begin{tabular}{ll|}
\hline P Projector! & \\
Please pick output units & \\
\hline meters & Cancel \\
\hline
\end{tabular}

Step 6: In the next menu, select the new projection. In this case, it is UTM-1983 Zone 16. Press 'OK' to reproject the file. If you are unsure what UTM zone your region is in, you can check it at this site: http://www.dmap.co.uk/utmworld.htm

Q Projection Properties
C. Standard C Custom
Category: UTM - 1983
Type: [IZone 16
Projection: Transverse Mercator
Spheroid: GRS 80
Central Meridian 87
Reference Latitude: 0
Scale Factor: 0.9996
False Easting: 500000
False Northing 0

